\title{
EL USO FIGURADO EN ALGUNOS CASOS DE UNIDADES PLURILEXEMÁTICAS: COLOCACIONES Y COMPUESTOS SINTAGMÁTICOS
}

\author{
$\mathrm{M}^{\mathrm{a}}$ Dolores MuÑoz NúÑEZ \\ Universidad de Cádiz \\ mdolores.munioz@uca.es
}

\begin{abstract}
Resumen
En este artículo se revisan algunas ideas que se han repetido con frecuencia en la bibliografía sobre colocaciones, sobre todo, las de que en una colocación se pueden distinguir dos elementos, colocativo y base, entre los que existe una direccionalidad, y que la base selecciona a veces del colocativo un uso figurado, con lo que se establece un mayor grado de cohesión entre ellos. No obstante, a partir de algunas estructuras sintagmáticas, vamos a analizar especialmente la incidencia en ellas del uso figurado y a proponer algunas pautas para distinguir entre colocaciones y compuestos sintagmáticos.
\end{abstract}

PALABRAS CLAVE: usos figurados, colocaciones, compuestos sintagmáticos.

\begin{abstract}
In this article some ideas which have often been repeated in the bibliography about collocations are revised, above all, the ones that two elements can be distinguished in a collocation, collocatif and base, between which there is a directional connection, and that the base sometimes selects a figurative use from the collocatif, so it is established a greater degree of cohesion between them. Nevertheless, from some syntagmatics structures, we are going to analyse especially the effect of the figurative use in them and to suggest some guidelines to distinguish between collocations and syntagmatics compounds.
\end{abstract}

KEY WORDS: figurative use, collocations, syntagmatics compounds

\section{Introducción}

En la abundante bibliografía sobre colocaciones hay un par de ideas que se han repetido en bastantes ocasiones: la primera -a partir de la concepción de colocación en Hausmann- es que en estas construcciones hay al menos una unidad autónoma, que coincide con la base, y otra "qui ne réalise pleinement son signifié qu'en combinación avec une base" (Hausmann, 1979: 192), el colocativo. Es lo que ocurre, según este autor, con célibataire endurci, base y colocativo respectivamente; y añade: "la base complète la définition du collocatif, alors que le collocatif se contente d'ajouter une qualité à une base en elle-même suffisamment définie" (idem).

La segunda idea a la que también se le ha prestado bastante atención es la de que el colocativo puede tener un uso figurado, y que tal uso figurado 
supone un factor de cohesión entre ese elemento y su base (a veces, incluso, se ha presentado esta circunstancia como muestra de la difícil delimitación entre colocaciones y locuciones y otras como prueba del paso de unas a otras, pero no del paso de las colocaciones a los compuestos sintagmáticos). La idea del uso figurado del colocativo nos invita a pensar, sin embargo, en que cuando la base selecciona del colocativo una acepción figurada no está del todo claro si la primera completa la definición del segundo o el colocativo se convierte también en una unidad dotada de una gran carga sémica -con más o menos autonomía, ya que autonomía y semantismo no se identifican-, y a veces muy especializada en relación con su base.

Atendiendo a la dependencia del colocativo respecto a su base, sobre todo cuando media una acepción figurada, a su semantismo y a los posibles efectos que provocan los usos figurados en la delimitación de ciertas unidades plurilexemáticas, queremos analizar a continuación las siguientes ideas:

a) si el colocativo es realmente un elemento con poco semantismo, atendiendo a lo que dice Hausmann de que sólo añade una cualidad a una base suficientemente definida; en este sentido, no tiene la misma carga semántica el verbo dar-verbo "ligero" o soporte (véase la distinción de Koike entre verbos funcionales y léxicos, 2001: 69)- en, por ejemplo, dar fe que caldearse en caldearse el ambiente;

b) hasta qué punto los usos figurados constituyen un factor importante en la conformación y delimitación de unidades plurilexemáticas como colocaciones y compuestos sintagmáticos por la menor o mayor cohesión y grado de transparencia que estos usos figurados provocan entre sus elementos constituyentes; es decir, ¿qué es lo que hace que pudiéramos considerar combinaciones como dar fe, caldearse el ambiente, o dinero negro ${ }^{1}$, rabiosa actualidad y afirmación gratuita como colocaciones, y agujero negro, aldea global, leche condensada o tela asfáltica como compuestos sintagmáticos si en todos esos casos interviene el uso figurado en la interpretación del significado?, y

c) si colocación y compuesto sintagmático constituyen dos fases de un proceso, el que conduce a la lexicalización de la colocación (como han señalado, como veremos, algunos autores), o bien se trata de unidades plurilexemáticas distintas.

Para nuestro análisis nos centraremos en el estudio de tres tipos de combinaciones, de los seis que señala, entre otros, Koike (2001: 44-60): sustanti-

$1 \quad$ Véase el trabajo de Ginebra (2002: 147-154) en relación con la interpretación de esta unidad como colocación. 
vo+adjetivo, sustantivo+de+sustantivo y verbo+sustantivo. Hemos seleccionado estos tres tipos de estructuras porque creemos que son estas las que más diversidad de opiniones generan respecto a su adscripción al ámbito de las colocaciones o de los compuestos sintagmáticos, sobre todo las dos primeras; la de verbo+sustantivo también, y sobre todo, al de las locuciones, y todo ello motivado en este caso por la menor o mayor preeminencia de usos figurados entre los elementos de este tipo de construcción. Pero sólo le prestaremos atención al cruce de opiniones respecto a si estamos en esta estructura ante un compuesto sintagmático, una colocación o una locución en este punto de nuestro trabajo, ya que en este caso la cuestión se dirime generalmente entre colocación y locución. En cuanto al resto de tipologías, resulta raro encontrar adscritos al menos a los compuestos sintagmáticos ejemplos como jugar sucio, perdidamente enamorado o salir redondo ${ }^{2}$.

Antes de seguir con nuestro análisis consideramos necesario aclarar que no desarrollaremos la idea de que, en nuestra opinión, el concepto de colocación es diferente al de restricción léxica (que implica toda una descripción teórico-práctica cuyo resultado es el diccionario $\operatorname{REDES}^{3}$ ), a pesar de que ambos son sintagmas donde un elemento puede exigir en menor o mayor medida la presencia del otro. La diferencia, como expusimos en Muñoz Núñez (2007: 189-194), reside básicamente en que las colocaciones son combinaciones frecuentes y preferentes, y en ellas la selección de una acepción del colocativo por parte de la base pierde relevancia. Es lo que ocurre en ardua tarea, aviesas intenciones, lucha intestina o mirada torva, donde, aunque podemos decir que los sustantivos son las bases y los adjetivos los colocativos, más bien lo que hay es una mutua "selección" léxica; es decir, cuando se quiere expresar el contenido que el colocativo "añade", en esos sintagmas existen muy pocas posibilidades de que este elemento se combine con otros sustantivos. Lo mismo ocurre en colocaciones con otra estructura, como la de verbo+sustantivo, donde se puede decir que los colocativos, que en estos casos son los verbos, dependen de los sustantivos, aunque lo que vuelve a funcionar realmente es una mutua "selección": dictar sentencia, proclamar autos, ratificar convenios, etc. (cf. Lorente Casafont, 2009: 70). El mismo comportamien-

2 En este sentido, hemos encontrado, no obstante, en el trabajo de Val Álvaro (1999: 4825), dentro de la composición sintagmática, ejemplos como perder la cabeza, sacar tajada, matar el polvo, hacer mención, poner orden, dar aviso, aunque este autor diga que, en las estructuras sintagmáticas fijadas de sintagma verbal, "no se produce la tendencia constatada en las nominales de fusión y cohesión en un compuesto perfecto" (op. cit.: 4831).

3 También de la teoría sentido-texto que, a partir de Mel'čuk, desarrolla Alonso Ramos (1994/95: 9-28; 2002: 63-96; 2009: 243-275) puede desprenderse la idea de restricción léxica, aunque la autora hable de colocaciones. 
to se observa cuando el colocativo tiene un uso figurado, como en los ejemplos citados anteriormente de rabiosa actualidad y afirmación gratuita (dejamos para más adelante el caso de dinero negro) o en los de dar fe, caldearse el ambiente, calentarse los ánimos o encender pasiones.

Por otra parte, la aparición de un uso figurado en uno de los elementos de las combinaciones desde rabiosa actualidad a encender pasiones -los colocativos, en estos casos- hace que también necesitemos aclarar que este hecho no convierte en absoluto tales combinaciones en idiomáticas. Es verdad que existen grados de transparencia u opacidad, lo que a veces dificulta su lectura, pero parece evidente que la lectura composicional siempre es en estos casos, de alguna manera, posible $e^{4}$ al contrario de lo que ocurre, en nuestra opinión, con las locuciones (y con no pocos casos de compuestos sintagmáticos). En concreto, ni caldearse el ambiente, calentarse los ánimos o encender pasiones aparecen como locuciones en el Diccionario fraseológico del español moderno (DFEM), de Kubarth y Varela (1994), ni el Diccionario de locuciones verbales para la enseñanza del español (DLVEE), de Penadés Martínez (2002). Eso no quiere decir que en estos tres casos, y, sobre todo, cuando se trata de la estructura verbo soporte+sustantivo, no exista diversidad de opiniones respecto a su adscripción, sobre todo, como colocaciones o como locuciones.

Así, atendiendo la estructura del verbo dar con un sustantivo (donde dar adquiere un uso figurado al gramaticalizarse en su combinación con los correspondientes sustantivos), hemos analizado si en estos diccionarios -a los que añadimos REDES y DEA ${ }^{5}$ - aparecen o no las siguientes combinaciones (que hemos seleccionado de un estudio inédito de Polakof ${ }^{6}$ sobre cons-

4 Son muchos los autores que coinciden en hablar de que, cuando media un uso figurado en el colocativo, el significado de la colocación es entonces parcialmente composicional (cf., entre otros, Corpas Pastor, 1996: 82-83; Koike, 2001: 175, quien señala incluso que este hecho la hace próxima a la locución; 2002: 7, 14-15; Zuluaga, 2002: 103, 105106), pero nunca hablan explícitamente de que la colocación haya dejado de ser composicional.

5 Se trata de dos diccionarios que, aunque con puntos de partida diferentes en cuanto a la indización de los lemas, contienen una información muy exhaustiva sobre la combinatoria de las unidades léxicas. Aunque REDES (Bosque, 2004) no es un diccionario ni de locuciones ni de colocaciones es el que más se acerca al segundo concepto, al entender que la colocación es un tipo de restricción léxica (cf. 2001: 10-11; 2002: 11-52). Por otra parte, el Diccionario del español actual (DEA), de Seco, Andrés y Ramos (1999), debe estar siempre presente cuando realizamos una labor de contraste entre diccionarios por las razones enunciadas al comienzo de la nota.

6 Esta autora ha realizado un estudio de 97 combinaciones del verbo dar+sustantivo (sujeto u OD) y ha obtenido los siguientes cruces comparando la información que aparece en REDES, el DFEM y el DLVEE: 
trucciones con el verbo dar en estos mismos diccionarios), y el resultado es el siguiente:

$\begin{array}{lcccc} & \text { DEA } & \text { REDES } & \text { DFEM } & \text { DLVEE } \\ \text { Dar alas } & \text { no } & \text { sí } & \text { sí } & \text { sí } \\ \text { Dar carpetazo } & \text { no } & \text { sí } & \text { sí } & \text { sí } \\ \text { Dar fe } & \text { no } & \text { sí } & \text { sí } & \text { no } \\ \text { Dar margen } & \text { no } & \text { sí } & \text { sí } & \text { no } \\ \text { Dar paso } & \text { no } & \text { sí } & \text { sí } & \text { sí }\end{array}$

Vemos, pues, que la gramaticalización del colocativo dar no es un factor que delimite claramente colocaciones de locuciones y que, por tanto, hay que hacer intervenir otros factores (hemos apuntado la idiomaticidad de las locuciones; cualquier estudio básico sobre el tema añadiría el hecho de que las locuciones constituyen por si mismas actos de habla o enunciados, pero también podrían considerarse de esta manera algunas colocaciones correspondientes a la estructura verbo+sustantivo). Puesto que el objetivo de este trabajo es analizar la incidencia del uso figurado en colocaciones y compuestos sintagmáticos, nos limitamos a hacer referencia a algunos trabajos que tratan de deslindar respecto de las nociones citadas también la de locución, como son los de Corpas Pastor (1996: 53-125), Zuluaga (2002: 105-107), Ruiz Gurillo (2002: 327-339) o Buenafuentes de la Mata (2007: 103-119).

\section{La intensión sémica del colocativo y su estatuto respecto a la base}

Abordemos ahora la idea de la carga sémica tan específica, especializada o figurada (cf. Llamas Saíz, 2007: 2152), que a veces los colocativos pueden llegar a tener. Penadés Martínez (2001: 71-72) afirma que hay colocaciones que tienen como base al verbo, como en despuntar el día, doblar la calle y doblar la esquina, retomando el análisis hecho por Hausmann en un trabajo de 1998, en el que se plantea la dificultad para definir el estatuto de base y colocativo en estos casos. En concreto, la autora señala que "es necesario revisar la idea de que el sustantivo es siempre la base de una colocación formada por un verbo y un sustantivo" (op. cit.: 76), y ello porque, junto a casos donde el verbo se ha desemantizado, como ocurre en las diferentes construcciones con el verbo dar, encuentra otros ejemplos donde tanto el colocativo como la base conservan su significado léxico respectivo.

\begin{tabular}{|l|l|l|}
\hline CRUCES & $\mathrm{N}=97$ & Porcentaje \\
\hline a) Restricción-Locución & 39 & 40,2 \\
\hline b) Colocación-Locución & 49 & 50,5 \\
\hline c) Restricción-Colocación-Locución & 9 & 9,3 \\
\hline
\end{tabular}


Lo que sucede es que en estos ejemplos de despuntar el día, doblar la calle, doblar la esquina, o en los de caldearse el ambiente, calentarse los ánimos o encender pasiones (lo mismo que en otras combinaciones donde no aparece ningún uso figurado, como en dictar sentencia, proclamar autos o ratificar convenios), el colocativo -el verbo en estos casos- tiene una acepción muy específica en relación con su base, independientemente de que ciertos sintagmas sean más propios de ciertos lenguajes especializados ${ }^{7}$, como los citados entre paréntesis. Lo mismo ocurre en ejemplos cuya estructura es la de sustantivo+adjetivo: rabiosa actualidad, inflación galopante, afirmación gratuita, lógica aplastante, etc., donde el colocativo parecería coincidir con el adjetivo. Es por ello que apuntamos al comienzo de este trabajo que autonomía y semantismo son dos conceptos distintos y que no parece apropiado afirmar que el colocativo simplemente añade una información a una base suficientemente definida.

Pero analicemos más detenidamente el estatuto de base y colocativo en estos casos, dejando a un lado el marco teórico en el que cada autor realiza su planteamiento, ya que ello no afecta a lo que queremos exponer. Es de todos conocida la idea de dependencia entre colocativo-base (desde el trabajo inicial de Hausmann, 1979: 187-195, donde se habla de combinación orientada), predicado-argumento (en el sentido que prima en el diccionario $\mathrm{REDES}^{8}$ ), o clase determinada-clase determinante (en la elaboración del concepto de solidaridades léxicas formulado por Coseriu, 1977a: 143-161). En un trabajo anterior (Muñoz Núñez, 2007: 189-194) analizamos lo que estas dependencias suponen, a nuestro entender, cuando afrontamos el estudio de las colocaciones y que lo que realmente se percibe, más que dependencia del colocativo respecto de la base, es el hecho de que la direccionalidad pierde relevancia, o, en otras palabras, la selección que opera uno de los elementos sobre el otro se convierte más bien en una mutua "selección". Y ello aunque, no sólo desde el punto de vista estricto del análisis sémico, sino también estadísticamente se pueda comprobar que en la coocurrencia de dos unidades léxicas el porcentaje de esta coocurrencia es mayor en un caso que en otro.

Está claro, como indica Bosque (2001: 12-13), que las aproximaciones estadísticas al concepto de colocación están lejos de las informaciones sobre el comportamiento selectivo de las unidades de una lengua, pero es una rea-

7 De hecho, para Firth el concepto de colocación surge en el ámbito de los lenguajes especializados (véase un breve recorrido historiográfico en Muñoz Núñez, 2007: 177-179). 8 En un artículo de Bosque (2001: 10) se explica que es el colocativo el que selecciona a su base. Entendemos que el concepto de selección utilizado por Bosque es muy particular, ya que el colocativo selecciona a su base porque depende de ella, aunque desde Hausmann se diga que la base selecciona del colocativo una determinada acepción. Creemos que son dos formas de expresar, en el fondo, el mismo hecho. 
lidad, como señalamos en Muñoz Núñez (op. cit.: 185), que ciertas combinaciones sólo presentan esta característica y no se pueden explicar de otra manera. Es lo que Haussmann calificó como "contrainte plus ou moins arbitraire des mots sur les mots, contrainte qui se révéle lors de la comparaison avec d'autres langues" (op. cit.: 191).

Koike (2001: 26) ejemplificó el tema de la coocurrencia entre los elementos de una colocación con la combinación medida drástica, analizada en el Diccionario Planeta de la lengua española usual (DP):

Frecuencia de medida: 250

Frecuencia de drástico: 8

Coocurrencia: 4

Porcentaje de coocurrencia de drástico con medida: 4/8x100=50\%

Porcentaje de coocurrencia de medida con drástico: 4/250x100=1,6\%

lo que indicaría que el elemento que depende de la base es drástico, por lo que este adjetivo es el supuesto elemento "no completo" (colocativo), que necesita combinarse con el sustantivo medida (base) para completar su significado.

En el fondo de este planteamiento subyace la idea de que cuando el colocativo presenta, sobre todo, un uso figurado la restricción de esta unidad para combinarse será mayor, aunque eso le haga perder productividad a un determinado paradigma (como señala Llamas Saíz, 2007: 2154). Pero, previamente, o no, la base ha seleccionado del colocativo una determinada acepción; por eso preferimos hablar insistentemente de mutua "selección". Por tanto, el colocativo puede ser una unidad tan dotada de semantismo como la base, pero además, al hablar de mutua "selección", la autonomía de la base puede ser tan relativa como la del colocativo.

E incluso se dan, aunque muy pocos, casos de colocativos con gran carga sémica donde no sea ni siquiera necesaria a veces la copresencia de las dos unidades de las colocaciones, y donde el elemento que aparezca sea el colocativo: son los casos de alazán (caballo alazán), bayo (caballo bayo) etc., ejemplos considerados por Coseriu como solidaridades léxicas, pero sobre los que argumentamos la posibilidad de incluirlos entre las colocaciones (Muñoz Núñez, op. cit.: 186-189), y en los que se produce un fenómeno análogo a la elipsis originada en combinatoria léxica (véase, sobre todo, el estudio pionero de Carbonero Cano, 1979: 177-185). Pero esto ocurre cuando el elemento determinado asume el contenido de todo el sintagma, lo que no sucede normalmente, sobre todo, cuando interviene un uso metafórico, ya que, como señala Llamas Saíz (op. cit.: 2153), el uso figurado obliga a la realización del elemento implicado al haberse producido una ruptura de la solidaridad léxica; son los casos, citados por esta autora, de cabalgar una tabla o morder el frío. 
Sin embargo, la escasa aparición del colocativo como representante del significado de todo el sintagma no impide que no podamos abordar posteriormente si se produce o no una progresiva lexicalización entre los elementos de una combinación hasta el punto de que tal combinación funcione como una unidad, tratando de responder a lo señalado en el apartado c) del comienzo de nuestro trabajo: si colocación y compuesto sintagmático constituyen dos fases de un proceso, el que conduce a la lexicalización de la colocación, o bien se trata de unidades plurilexemáticas distintas. Y es que el fenómeno de la elipsis al que aludimos tampoco se da cuando lo que tenemos es un compuesto sintagmático como los citados en este trabajo. Así, no hay omisión de ninguno de los elementos de los que de momento consideramos compuestos sintagmáticos como ojo de buey, paso de cebra, como tampoco hay omisión en los casos de máquina de escribir o diario de navegación, donde ningún elemento parece presentar un uso figurado.

Sí ha habido elipsis (cf. Carbonero Cano, op. cit.: 183-184) en casos como los de tren metropolitano $\rightarrow$ metro, reloj despertador $\rightarrow$ despertador, estación terminal $\rightarrow$ terminal (que, actualmente, se ha especificado de nuevo con un sintagma preposicional: terminal de autobús, terminal de un aeropuerto, etc.), cigarro puro $\rightarrow$ puro, barco de vapor $\rightarrow$ vapor, tren de mercancías $\rightarrow$ mercancías, etc., donde quizá la elipsis representaría el máximo de lexicalización.

\section{El papel de los usos figurados en la delimitación entre colocaciones y compuestos sintagmáticos}

Retomemos la estructura sustantivo+de+sustantivo, menos analizada que la de sustantivo+adjetivo, con ejemplos como los citados de ojo de buey, paso de cebra, o cortina de humo y niña del ojo (que no parecen diferenciarse de los también citados máquina de escribir, diario de navegación o fin de semana porque uno de los elementos de la construcción presente o no un uso figurado), para ver hasta qué punto los usos figurados constituyen un factor importante en la conformación y delimitación de colocaciones y compuestos sintagmáticos por la menor o mayor cohesión que provocan entre sus elementos constituyentes y por los distintos grados de transparencia que afectan a los sintagmas correspondientes, aspectos que se han venido presentando, en la bibliografía sobre el tema (cf., sobre todo, Koike, 2001: 174-177; 2002: 5-6, 14-18), como características de las colocaciones.

Hasta donde hemos podido comprobar de momento, si bien la incidencia de los usos figurados puede determinar para algunos autores la adscripción de una unidad a las colocaciones o a las locuciones (aunque para otros la aparición de 
un elemento con un uso figurado es, sin más, algo característico de muchas colocaciones), porque prime o no el criterio de la idiomaticidad, no está tan clara esta incidencia en la determinación de lo que es colocación o compuesto sintagmático. Así, Zuluaga (2002: 104), aludiendo a las colocaciones (o enlaces frecuentes, según la terminología de Moliner), afirma que "estas combinaciones son conocidas y empleadas como unidades compuestas, son de uso general, de dominio colectivo"; pero anteriormente ha citado los casos de pena de muerte y sentido del humor, sobre todo, como ejemplos de colocaciones (op. cit. 103).

Hemos revisado en dos diccionarios de la lengua española, el DRAE y el DEA (que, al ser diccionarios generales, tendrían que recoger, al menos, el fenómeno de lexicalización que se produce en los compuestos sintagmáticos), los casos de ojo de buey, paso de cebra, cortina de humo y niña del ojo, y el resultado ha sido el siguiente: 1) en ambos diccionarios aparecen todas estas unidades, aunque sin especificar si son compuestos o combinaciones frecuentes, es decir, colocaciones; 2) sólo en el caso de cortina de humo aparece en el DRAE la especificación "fig. Mar. y Mil." y sólo la acepción "Masa densa de humo, que se produce artificialmente para ocultarse del enemigo". En cambio, en el DEA no aparece ninguna especificación y sí exclusivamente la acepción que nos interesa, "Asunto con que interesadamente se distrae la atención general respecto a otro", al ser completamente figurada por parte de los dos elementos de la combinatoria.

Si comparamos los casos anteriores con los de rabiosa actualidad, inflación galopante o afirmación gratuita, por ejemplo, para ver si las posibles diferencias entre las combinaciones con la estructura sustantivo+adjetivo y las que presentan la estructura sustantivo+de+sustantivo residen en la mayor o menor opacidad sintagmática de estas últimas, parecería evidente que la idiomaticidad es mayor en los casos de la segunda estructura, aunque también es verdad que parece igualmente evidente que en estos casos, y no en los de rabiosa actualidad, inflación galopante o afirmación gratuita, estamos ante unidades de denominación (pensemos, de la misma manera, si fin de semana, diario de navegación o máquina de escribir, que no presentan ningún uso figurado, son unidades de denominación).

Pero antes de abordar otros criterios en la delimitación entre colocaciones y compuestos sintagmáticos, es necesario considerar la incidencia de los usos figurados en cualquier sistema lingüístico y, en concreto, en la posible delimitación de unidades. Con ello no queremos entrar en la polémica de si los usos figurados constituyen hechos de habla y no de lengua, atendiendo a la visión "clásica" de Coseriu en afirmaciones como las de que "la 'lengua' no nos es nunca enteramente suficiente para expresarnos en cada caso particu- 
lar, dado que nuestras intuiciones [...] no son nunca idénticas a otras anteriores. La creación es, pues, constante en el lenguaje; no caracteriza sólo el momento inicial de un símbolo [...], sino todo acto de hablar" (1977b: 75) o "es verdad también que, científicamente, comprobamos los hechos de creación cuando ya se han constituido en 'lengua' (actividad repetida), es decir, cuando ya se han aceptado como modelos por más de un individuo, cuando la creación se ha hecho en cierta medida 'convención'" (op. cit.: 76).

$\mathrm{Si}$, en cambio, tenemos en cuenta cómo está configurado, por ejemplo, el diccionario REDES, encontramos las siguientes palabras de su autor (2001b: 40) ante el manejo de los usos figurados a la hora de seleccionar lo que este autor denomina "restricciones léxicas":

Muchos predicados imponen a sus argumentos restricciones severas en las interpretaciones figuradas, y muy débiles en las puramente físicas. El DRL distinguirá unas de otras y restringirá, por tanto, la descripción de los elementos seleccionados a dichas interpretaciones no físicas. Consideremos, por ejemplo, el verbo acariciar. Carecería de sentido proporcionar una lista de objetos o personas que pueden ser acariciados [...]. Resulta, en cambio, de interés proporcionar la lista, mucho más restringida, de nociones que pueden ser "acariciadas", en la interpretación figurada de acariciar. Entre esos sustantivos están idea, triunfo, proyecto, plan, posibilidad y algunos más.

Coseriu es uno de los principales exponentes del estructuralismo europeo de la década de los sesenta en adelante. En cuanto a Bosque, si bien sus trabajos se enmarcan generalmente en una línea teórica generativista, su proyecto -luego diccionario- de restricciones léxicas adopta una visión muy particular respecto a nociones como las de predicado y argumento y el propio concepto de selección léxica (véase la nota 8).

Aunque querríamos despojar este estudio, si es posible, de cualquier vinculación a una tendencia lingüística determinada, la mayoría de las opiniones vertidas sobre el papel de los usos figurados se realiza dentro de un marco teórico concreto. Por eso, no podemos olvidar tampoco lo que desde una óptica cognitivista en sentido amplio ${ }^{9}$ se ha argumentado al respecto. Así, por ejemplo, siguiendo una línea que va desde Lakoff y Johnson (1980), Indurkhya (1992), Rivano Fischer (1997), hasta los trabajos recapituladores, en el ámbito hispánico, de Azevedo (1997) o Llamas Saíz (2005), podemos utilizar, a modo de síntesis, las palabras de Lakoff y Johnson (1980: 3) sobre el lugar que los usos figurados ocupan desde una visión cognitivista de la lengua:

La metáfora es para la mayoría de la gente un artificio de la imaginación poética y la ornamentación retórica -algo que pertenece al lenguaje extraor-

9 Véase el estudio compilador de Merino Ferradá (1993: 211-241) sobre las distintas formas de entender el cognitivismo. 
dinario, más que al lenguaje ordinario. Además, típicamente se ve a la metáfora como algo característico sólo del lenguaje, un asunto de palabras, más que del pensamiento y la acción. Por esta razón, la mayoría de la gente piensa que puede arreglárselas perfectamente bien sin la metáfora. Hemos encontrado, por el contrario, que la metáfora es prevalente en la vida cotidiana, no sólo en el lenguaje, sino también en el pensamiento y la acción. Nuestro sistema conceptual, en términos del cual pensamos y actuamos, es fundamentalmente metafórico en su naturaleza ${ }^{10}$.

Así pues, las diferentes posturas sobre el tema van desde la necesidad de adscribir los usos figurados al plano del habla y no al de la lengua hasta la no distinción de planos para su consideración. Pero lo que más nos interesa resaltar en este momento es que, según lo que venimos observando en los ejemplos de estas páginas, cuando se habla de usos figurados estos no parecen presentarse como un factor que delimite unidades, al menos, hasta el momento, no nos han servido para delimitar colocaciones y compuestos sintagmáticos. Y es que, en nuestra opinión, el uso metafórico es un "fenómeno" transversal, ya que afecta a muchos hechos lingüísticos sin poder delimitarlos a todos por esa circunstancia. Pueden hacernos modificar la carga sémica de una acepción, para otros autores, simplemente hacer variar su extensión (cf. Bosque, 2004: CXI), lo que consideramos dos caras de la misma moneda, provocar distintos grados de transparencia y una mayor cohesión semántica entre los elementos constituyentes de un sintagma, pero tendremos que hacer intervenir otros factores para una adecuada delimitación de los dos conceptos que nos vienen ocupando.

\section{Otros criterios en la delimitación entre colocaciones y compuestos sintagmáticos. El concepto de unidad de denominación}

Llegados a este punto, se hace, pues, necesario recordar los criterios que se han dado para la delimitación de los compuestos sintagmáticos, en comparación con los que se han dado para delimitar colocaciones. Posteriormente, abordaremos la cuestión de si colocaciones y compuestos sintagmáticos constituyen o no dos fases de un mismo proceso.

Entre las varias características de los compuestos sintagmáticos que señala Val Álvaro (1999: 4763-4765), nos interesa destacar, sobre todo por la discusión sobre si tales características establecen realmente límites estrictos entre compuestos sintagmáticos y colocaciones $^{11}$, las de que en los primeros

10 Traducción de Rivano Fischer (1997: 30).

11 En cambio, parece que sí serían definitivas para la determinación de compuestos sintagmáticos pruebas como el hecho de que sólo el núcleo acepta la flexión (fin/fines de 
estamos ante una unidad de denominación, ya que no existe la realidad designada por el conjunto en las partes consideradas separadamente; por tanto, como tal unidad, no cabe esperar que haya coordinación de sintagmas con elipsis del núcleo, conversión de la combinación correspondiente en una oración atributiva ni ningún proceso de relativización. De esta manera, creemos que no resultan aceptables expresiones como:

* ojo de buey y de persona / el ojo es de buey / que es de buey

* paso de cebra y de caballo / el paso es de cebra / que es de cebra

* cortina de humo y de raso / la cortina es de humo / que es de humo

ni tampoco estas otras donde los compuestos sintagmáticos presentan la estructura sustantivo+adjetivo (aunque con algún posible caso aceptable):

* agujero negro y profundo / el agujero es negro / que es negro

* aldea global y aislada / la aldea es global / que es global

* leche condensada y desnatada / la leche es condensada / que es condensada

En cambio, aunque resultan problemáticas a veces, a lo mejor podríamos aceptar expresiones como:

- ¿? inflación fuerte y galopante /la inflación es galopante / que es galopante

- afirmación gratuita y desafortunada / la afirmación es gratuita / que es gratuita

- lógica aplastante y definitiva / la lógica es aplastante / que es aplastante,

quizá porque el "ojo que es de buey" no funciona como explicación y sí la "inflación que es galopante" o la "afirmación que es gratuita". No entraremos de momento en que la posible inaceptabilidad de las coordinaciones y relativizaciones de los elementos en las secuencias inflación galopante, afirmación gratuita y lógica aplastante reside en que los adjetivos no funcionan como calificativos sino como argumentales o clasificadores (cf. Ginebra, 2002: 149 a propósito de dinero negro), porque parece que tales adjetivos, galopante, gratuita y aplastante, pertenecen a la subclase de los calificativos absolutos, de manera que no se puede decir inflación muy galopante, afirmación muy gratuita o lógica muy aplastante, del mismo modo que no se puede decir de algo que es muy cuadrado o muy redondo, utilizando ahora la prueba de si los adjetivos en cuestión aceptan o no cuantificadores de grado (cf. Ma D. Muñoz, 2010, en prensa), aunque posiblemente sí acepten otros adverbios (cf. la nota 11).

semana, ojo/ojos de buey, etc.), la no alteración del orden de los constituyentes y la no inclusión de ninguna otra categoría gramatical entre ellos (en cambio, en el caso de las colocaciones, a veces sí es posible intercalar alguna otra categoría gramatical: afirmación absolutamente gratuita, lógica realmente aplastante). 
Pero detengámonos exclusivamente en el hecho de que en los compuestos sintagmáticos estamos ante una unidad de denominación, porque ello enlaza con una de las pruebas que se han dado para determinar lo que es una colocación: el hecho de que en este ultimo tipo de unidad hay una estructura común, ya que en ellas es posible distinguir dos componentes, base y colocativo (cf. Corpas Pastor, 1996: 51, 56-59), lo que no sucede en los compuestos sintagmáticos, en los que estamos ante una "única unidad de sentido" o "un significado añadido, imprevisible, que no se desprende directamente de la suma del significado de sus elementos integrantes" (Ferrando Aramo, 2002: 101). No vamos a volver a la idea de que, en nuestra opinión, base y colocativo se pueden distinguir en bastantes casos, pero en muchos otros la direccionalidad pierde relevancia. Lo que sí vamos a someter ahora a discusión es la vinculación entre el modo de significar de los compuestos sintagmáticos y su mayor grado de idiomaticidad, frente a las colocaciones.

En efecto, parece evidente que ejemplos como agujero negro, aldea global, leche condensada, tela asfáltica, ojo de buey, paso de cebra, cortina de humo o niña del ojo son compuestos sintagmáticos porque constituyen unidades de denominación, es decir, aluden a un referente único y no se pueden explicar composicionalmente (además de porque a sus componentes no se les puede aplicar las pruebas indicadas anteriormente). Pero también son compuestos sintagmáticos máquina de escribir, diario de navegación o fin de semana, y no precisamente porque funcione la correspondencia entre referente único y mayor grado de idiomaticidad. En el caso de la estructura sustantivo+adjetivo, Ferrando Aramo (op. cit.: 102) señala que en las colocaciones de este tipo el adjetivo tiene una función meramente intensificadora (odio mortal, voluntad férrea, amor imperecedero), mientras que en el compuesto sintagmático el adjetivo es especificador, clasificador, tiene una función restrictiva respecto del sustantivo (barco pesquero, avión comercial, vía rápida). Por tanto, estaríamos hablando incluso en estos casos de un subconjunto dentro de un referente único.

Podríamos estar tentados a argumentar que rabiosa actualidad, inflación galopante, afirmación gratuita y lógica aplastante también son unidades de denominación, porque en todos estos sintagmas el combinado designa una subclase dentro de las de actualidad, inflación, afirmación o lógica. Creemos, sin embargo, que la función del adjetivo, que en todos estos casos es calificativo, y no relacional (en cambio, en dinero negro es relacional), es muy importante para decidir que no estamos ante unidades de denominación, es decir, ante compuestos sintagmáticos. Y es que pensamos que es la idea de unidad de denominación, y no la de mayor grado de idiomaticidad (como hemos tra- 
tado de argumentar en el punto 3.), la que constituye el factor decisivo en la determinación de estos (cf. Ferrando Aramo, op. cit.: 104). No obstante, este planteamiento debe pasar necesariamente por la consideración, expuesta ya por distintos autores, de si existe un continuum entre colocaciones y compuestos sintagmáticos.

No querríamos entrar en la supuesta argumentación fácil de la existencia de este continuum a la hora de afrontar el tratamiento de algunas unidades plurilexemáticas, pero se ha hablado mucho de este hecho como para omitirlo. Decimos supuesta argumentación fácil porque, como veremos, no se debe abusar de la idea de continuidad en Lingüística, pero es de nuevo una realidad que ciertos hechos no se pueden explicar de otra manera. No obstante, como señala Zuluaga (2002: 98-99),

el reconocimiento expreso de la gradualidad de los hechos de lenguaje, gradualidad que, por cierto, dificulta o impide establecer fronteras claras entre las distintas clases de fenómenos [...] no debe ser obstáculo insalvable para definir claramente las categorías y los conceptos del análisis.

En un marco teórico distinto, y a propósito de las ventajas e inconvenientes de la aplicación del concepto de "continuidad" en Lingüística, Moure (1996: 273) manifiesta que

no se trata de expandir la hipótesis de continuidad por encima de sus posibilidades. Se trata, simplemente, de respetar la conformación que la realidad adopta, al menos en ciertas esferas, y organizar un entramado conceptual acorde con ella, que guíe nuestras predicciones y se adapte fielmente a la naturaleza del lenguaje. La continuidad sin extremos queda abiertamente excluida por su esterilidad y sólo se reivindica la pertinencia de casos intermedios, que escapan a divisiones burdas y exigen su propia metodología. Más allá de este límite, cualquier exceso debe ser rechazado.

Pues bien, desde los primeros trabajos de Corpas Pastor (1989: 114) hasta los más recientes de Ruiz Gurillo (2002: 332) o Blasco Mateo (2002: 4142) se ha hablado de la existencia de un continuum que va de las colocaciones a los compuestos sintagmáticos (y a las locuciones). Y también se ha insistido por parte de algunos autores en que "el hecho de caracterizar los distintos tipos de fraseologismos como formantes de una gradación no ha de suponer ambigüedad o vaguedad" (Blasco Mateo, op. cit.: 42). Pensamos, en efecto, que los estadios bien definidos y delimitados existen, y que al continuum sólo hay que darle la importancia relativa de constituir el proceso según el cual una unidad termina lexicalizándose. Pensamos también que ciertas estructuras son más proclives a la lexicalización que otras, la que más la de sustantivo+de+sustantivo y la que menos, en nuestra opinión -de acuerdo con los planteamientos de Buenafuentes de la Mata (2007: 92-93)-, la de 
verbo+sustantivo, a pesar de que Blasco Mateo señala "que estructuras como 'verbo-(artículo)-sustantivo' o 'sustantivo-de-sustantivo' constituyen en la lengua española esquemas perfectamente disponibles para la lexicalización" (Blasco Mateo, 2002: 36). En un lugar intermedio se encuentra la estructura sustantivo+adjetivo, en la que lo que puede facilitar la lexicalización, como hemos tratado de demostrar, es el papel del adjetivo en cuestión, y no exactamente factores cognitivos, entre otros.

\section{Conclusiones}

A lo largo de estas páginas hemos afrontado principalmente la incidencia de los usos figurados en la posible delimitación entre colocaciones y compuestos sintagmáticos. En nuestro análisis hemos tratado de desterrar algunos tópicos que se repiten en la bibliografía sobre el tema, a saber:

- que en las colocaciones se puede distinguir siempre claramente entre un colocativo y una base, y que el primero añade una cualidad a una base bien conformada semánticamente, autónoma;

- que cuando la base selecciona del colocativo un uso figurado se produce una mayor cohesión entre los elementos constituyentes de una colocación, y

- que el paso de un mayor grado de transparencia a un mayor grado de opacidad establece claramente la diferencia entre colocaciones y compuestos sintagmáticos, por lo que el hecho de que la idiomaticidad sea máxima permite considerar claramente una unidad plurilexemática como compuesto sintagmático (ni qué hablar que se ha recurrido a este mismo hecho para explicar el paso de colocación a locución, sobre todo en el caso de la estructura verbo+sustantivo).

Por el contrario, hemos argumentado que:

- muchas veces es difícil distinguir entre colocativo y base, ya que ambos elementos pueden tener una gran intensión sémica, y, además, entre ellos no existe exactamente direccionalidad sino mutua selección léxica;

- los diferentes grados de transparencia u opacidad no inciden en la delimitación entre colocaciones y compuestos sintagmáticos, en ninguno de los tres tipos de estructuras que hemos analizado;

- es la idea de unidad de denominación la que define el compuesto sintagmático; entendemos por unidad de denominación tanto aquella que se corresponde con un referente único, para el que no existía nombre, como aquella que indica una subclase de un referente; a tal operación 
se llega, al menos en los casos de la estructura sustantivo+adjetivo, gracias a la presencia en el sintagma de un adjetivo relacional, y

- no obstante estas consideraciones, y aunque también existen pruebas de comportamiento morfológico y sintáctico para distinguir entre colocaciones y compuestos sintagmáticos, a veces la unidad de denominación se configura más allá de estos criterios, porque la estructura se adapte más a nuestra forma de conceptuar (como en el caso de la de sustantivo+de+sustantivo), y ello porque la lengua, por factores como el que hemos citado u otros, como los sociológicos, pragmáticos, cognitivos o propiamente lingüísticos (cf. Blasco Mateo, op. cit.: 36) recategoriza sus unidades, lo que se explica en el marco de un proceso continuo que va de la gramaticalización a la lexicalización, de la misma manera que acontece el proceso inverso.

\section{Referencias bibliográficas}

Alonso Ramos, M. (1994/95): "Hacia una definición del concepto de colocación: de J. R. Firth a I. A. Mercuk", Revista de Lexicografía, 1, págs. 9-28.

Alonso Ramos, M. (2002): "Colocaciones y contorno de la definición lexicográfica", Lingüística Española Actual, 24, 1, págs. 63-96.

Alonso Ramos, M. (2009): "Delimitando la intersección entre composición y fraseología”, Lingüística Española Actual, 31, 2, págs. 243-275.

Blasco Mateo, E. (2002): "La lexicalización y las colocaciones", Lingüística Española Actual, 24, 1, págs. 35-61.

Bosque, I. (2001): "Sobre el concepto de 'colocación' y sus límites, Lingüística Española Actual, 23, 1, págs. 9-40.

Bosque, I. (2002): "Bases para un diccionario de restricciones léxicas", Moenia, 7, págs. 11-52.

Bosque, I. (2004): REDES. Diccionario combinatorio del español contemporáneo. Madrid, SM.

Buenafuentes de la Mata, C. (2007): Procesos de gramaticalización y lexicalización en la formación de compuestos en español. Barcelona, Universidad Autónoma de Barcelona (Tesis doctoral).

Carbonero Cano (1979): "Léxico autónomo procedente de combinatoria léxica", Estudios paraguayos, 7, 1, págs. 177-185.

Coseriu, E. (1977a): "Las solidaridades léxicas", Principios de semántica estructural. Madrid, Gredos, págs. 143-161.

Coseriu, E. (1977b): "La creación metafórica en el lenguaje", El hombre y su lenguaje. Madrid, Gredos, págs. 66-102.

Corpas Pastor, G. (1989): Estudio contrastivo de las colocaciones en inglés y en español. Su tratamiento lexicográfico con especial atención al tipo $A+S / S+A$. Málaga, Universidad de Málaga. 
Corpas Pastor, G. (1996): Manual de fraseología española. Madrid, Gredos.

De Azevedo, A. (1997): El lugar de la metáfora. Montevideo, Librería de la Facultad de Humanidades y Ciencias de la Educación.

Ferrando Aramo, V. (2002): "Colocaciones y compuestos sintagmáticos: dos fenómenos léxicos colindantes?”. En Veiga, A., M. González Pereira y M. Souto Gómez (eds.): Léxico y gramática. Lugo, Ediciones Tris Tram, págs. 99-107.

Hausmann, F. J. (1979): "Un dictionnaire des collocations est-il possble?", Tralili, XVII,1, págs. 187-195.

Indurkhya, B. (1992): Metaphor and Cognition. An Interactionist Approach. Dordrecht, Kluwer Academic Publishers.

Koike, K. (2001): Colocaciones léxicas en el español actual: estudio formal y léxicosemántico. Alcalá de Henares, Universidad de Alcalá, Takushoku Univiersity.

Koike, K. (2002): "Comportamientos semánticos en las colocaciones léxicas", Lingüística Española Actual 24, 1, págs. 5-23.

Kubarth, H. y F. Varela (2004): Diccionario fraseológico del español moderno. Madrid, Gredos.

Lakoff, G. y M. Johnson (1980): Metaphors We Live by. Chicago, The University of Chicago Press.

Llamas Saíz, C. (2005): Metáfora y creación léxica. Pamplona, Eunsa, Ediciones Universidad de Navarra.

Llamas Saíz, C. (2007): "Apuntes sobre la relación entre colocación y metáfora". En P. Cano López et alii (eds.): Actas del VI Congreso de Lingüística General. Madrid, Arco/Libros, págs. 2151-2162.

Lorente Casafont, M. (2009): "Verbos y fraseología en los discursos de especialidad". En M. Casas Gómez (dir.) y R. Márquez Fernández (eds.): XI Jornadas de Lingüística. Homenaje al Profesor José Luis Guijarro Morales. Cádiz, Servicio de Publicaciones Universidad de Cádiz, págs. 55-84.

Merino Ferradá, M. C. (1993): "La pragmática de los conceptos”, Pragmalingüística, 1, págs. 211-243.

Moure, T. (1996): La alternativa no-discreta en Lingüística. Una perspectiva histórica y metodológica. Santiago de Compostela, Servicio de Publicaciones Universidad de Santiago.

Muñoz Núñez, Ma D. (2007): "Colocaciones y restricciones léxicas: criterios de diferenciación”, Estudios de Lingüística Hispánica. Cádiz, Servicio de Publicaciones de la Universidad de Cádiz, págs. 177-198.

Muñoz Núñez, Mª D. (2010): "Algunos aspectos de la cuantificación de grado (con especial atención a la llamada "cuantificación de grado verbal")", Nueva Revista de Filología Hispánica (El Colegio de México), 58, 2, en prensa.

Penadés Martínez, I. (2001): “¿Colocaciones o locuciones verbales?”, Lingüística Española Actual, XXIII, 1, págs. 57-88.

Penadés Martínez, I. (2002): Diccionario de locuciones verbales para la enseñanza del español. Madrid, Arco/Libros. 
Polakof, A. C. (2007): Distinción entre colocaciones, restricciones léxicas y locuciones. Construcciones con el verbo 'dar' (Monografía de Licenciatura inédita dirigida por $M^{a}$ D. Muñoz Núñez, Universidad de la República, Uruguay).

Rivano Fischer, E. (1997): Metáfora y Lingüística Cognitiva. Santiago de Chile, Bravo y Allende Editores.

Ruiz Gurillo, L. (2002): "Compuestos, colocaciones, locuciones: intento de delimitación”. En A. Veiga, M. González Pereira y M. Souto Gómez (eds.): Léxico y Gramática. Lugo, Tris Tram, págs. 327-339.

Seco, M., O. Andrés y G. Ramos (1999): Diccionario del español actual. Madrid, Aguilar. Val Álvaro, J. (1999): "La composición". En I. Bosque y V. Demonte (dirs.): Gramática descriptiva de la lengua española. Madrid, Espasa, vol. 3, págs. 4757-4838.

Zuluaga, A. (2002): "Los “enlaces frecuentes" de María Moliner. Observaciones sobre las llamadas colocaciones”, Lingüística Española Actual, vol. XXIV/1, págs. 97-114. 